\title{
Gross Anatomy of the Splanchnocranium in the Great Indian Horned Owl (Bubo bengalensis)
}

\author{
K. Rajalakshmi*, P. Sridevi and M. Siva Kumar \\ Department of Veterinary Anatomy and Histology, Rajiv Gandhi Institute of Veterinary \\ Education and Research, Kurumbapet, Puducherry-605010, India \\ *Corresponding author
}

A B S T R A C T

\begin{tabular}{|l|}
\hline K e y w o r d s \\
Premaxilla, \\
Maxilla, \\
Pterygoid, \\
Lacrimal \\
\hline Article Info \\
\hline Accepted: \\
12 February 2020 \\
Available Online: \\
10 March 2020 \\
\hline
\end{tabular}

A study was conducted on the gross features of the splenchnocranium of an aged great Indian horned owl and its morphological peculiarities were correlated with its possible functions. The horizontal plate of ethmoid was wide and well developed. The lacrimal was very large and the lower orbital ring was incomplete. The external nares were oval in shape. The premaxilla was steeply curved down and had a hooked tip. The maxilla was highly reduced and formed a movable articulation with the palatine and zygomatic bone. The rod like zygomaticus formed a movable articulation rostrally with the maxilla and caudally with quadrate. The paired palatines were horizontal in position and formed the strong bone of the upper jaw. The pterygoid was a thin short and which articulated cranially with palatine, behind with parasphenoid process of presphenoid and caudally with quadrate. The quadrate was semi-circular.

\section{Introduction}

The splanchnocranium (bones of the face) is clearly demarcated from the neurocranium by the orbital cavities. The size of splanchnocranium is largely dependent on the diet and feeding habits of the bird (Nickel et al., 1986). The birds rostrum is composed of teeth less jaws covered by a honey sheath, known as the ramphotheca. Birds jaws are powerful tools used for feeding, especially in the birds of prey. The temporal and antiorbital fenestrae in both paleognaths and neognaths have merged with the orbit (Knutsen, 2007). An important feature of birds is cranial kinesis which is the movement of the upper jaw in relation to the brain case. It is generated by a complex mechanism in the skull. Since the quadrate bone articulates with the brain case, pterygoid bones, jugal arches and mandible are pivoting points in cranial kinesis. The Indian eagle-owl also 
called the rock eagle owl or Bengal eagle-owl is a species of large horned owl restricted to the Indian subcontinent. Their diet through much of the year consists of rodents, when feeding on rodents, they tear up the prey, rather than swallow them whole. This large owl with distinctive face, large forwardfacing eyes, horns and deep resonant call is associated with a number of superstitions. Gross morphological studies on the skull of domestic fowl, pigeon and goose have been discussed in various text books of Anatomy (Nickel et al., 1986). However, not much information is available on the skull of owl. Hence the present study was undertaken to investigate the morphological variations in the splanchnocranium and to correlate it with their possible functions.

\section{Materials and Methods}

The materials for the study were collected from owl brought for post mortem examination to the Department of Veterinary Pathology Rajiv Gandhi Institute of Veterinary Education and Research, Puducherry. The bones were removed and collected by the regular process of maceration, cleaned, dried and the various gross anatomical features were recorded.

\section{Results and Discussion}

The bones of the splachnocranium comprised of the lacrimal, nasal, premaxilla, maxilla, zygomatic, palatine, Pterygoid, vomer, quadrate and mandible. The ethmoid was shared by both neurocranium and splachnocranium (Nickel et al., 1986).

The ethmoid consisted of two parts namely the horizontal and perpendicular plate. The horizontal plate was located craniodorsally and formed the anterior wall of the orbit of separated the orbit from the nasal cavity. It was wide well developed in the owl and had the paired olfactory foramen for the passage of olfactory nerves into the nasal cavity. The thick perpendicular plate of ethmoid formed the interorbital septum along with the orbital plates of frontal joined the nasal septum rostrally. A similar observation was reported by Indu et al., 2013 in green-winged macaw. However in domestic fowl and Japanese quails, the ethmoid was thin and small and formed the cranio-dorsal wall of the orbit and the olfactory foramen was located in the dorsomedial part of the perpendicular plate (Fitzgerald, 1969, Nickel et al., 1986). John et al., 2016 in crow reported that the horizontal part was reduced. The wide horizontal plate of ethmoid in owl could be a means of adaptation to accommodate the well developed nasal, lacrimal and premaxilla. Moreover it also formed the strong posterior base of the cranio-facial hinge.

The interobital septum was pierced by the interorbital septal notch which was located rostrally and below the olfactory foramen. The optic foramen was smaller and was smaller and was placed far behind the interorbital septal notch. John et al., 2016 mentioned that the optic foramen was located adjacent to the caudal boundary of the notch in crow.

\section{Lacrimal}

The lacrimal was very large and was fused with the frontal bone behind and formed a movable articulation with the nasal bone in front called as cranio-facial hinge. It consisted of two lacrimal process dorsal and ventral. The dorsal lacrimal process (Fig.1) was short triangular in outline and its apex faced towards the orbit. Whereas Indu et al., 2013 observed a caudo-ventrally directed lacrimal process in green-winged macaw. Moreover, in duck, fowl and Japanese quail, the lacrimal process was absent and the ventral wall of the orbit was incomplete 
(Fitzgerald, 1969 and Nickel et al., 1986). The ventral lacrimal process was an elongate flattered bony plate. John et al., 2016 also noticed a well developed ventrally directed lacrimal process in crow. It was caudally or caudo ventrally directed and faced the orbital process of quadrate being separated from it by a considerable space. Hence, an incomplete lower orbital ring was noticed. However, Indu et al., 2013 in green-winged macaw stated that the caudo-ventrally directed lacrimal process fused with the orbital process of temporal and formed a small nearly circular complete lower orbital ring.

\section{Nasal}

Nasal bones formed a part of the upper beak and a greater part of the roof of the nasal cavity. It comprised of three well developed processes namely the frontal, maxillary and intermaxillary process. A similar observation was reported by Nickel et al., 1977 in domestic fowl. The frontal process of nasal was fused with the nasal part of the frontal bone. The dorsal face of the frontal process of the nasal bone presented the infra orbital foramen. The intermaxillary process of nasal bone formed the dorsal boundary of the external nares. The maxillary process formed the lower boundary of the external nares. According to John et al., 2016, in crow, the lateral process of nasal bone formed the aboral and lower borders of the nares. The external nares or operculum was oval in shape in owl.

The nostrils were positioned towards the base of the beak, in a region called the cere. A well-developed naso frontal hinge or cranio facial hinge was formed due to the articulation between frontal process of nasal bone with the cranial border of the frontal. A similar observation was reported in crow by John et al., 2016.

\section{Premaxilla}

The paired premaxilla formed the largest part of the upper jaw and was covered by the horny beak. It had a body and three processes, the frontal, palatine and maxillary process as reported by Nickel et al., 1977 in domestic fowl and Indu et al., 2013 in greenwinged macaw. Maxillary process supported part of the beak and was fused with the maxilla. Palatine process was very large and spongy and united with each other and with the ossified nasal septum and occupied the entire base of the beak. However, Nickel et al., 1986 in fowl reported that the palatine processes were very narrow with a broad cleft in between them. The frontal process were medially fused and reached up to the frontal bone. The maxillary and intermaxillary process of nasal bone was fused with the frontal and maxillary process of premaxilla. (Fig.2).

\section{Maxilla}

The maxilla was highly reduced and formed the caudal boundary of the upper beak. John et al., 2016 had also reported a highly reduced maxilla in the crow. It was fused with the nasal and premaxilla. It had two processes, the palatine and zygomatic which formed movable articulations with the palatine and zygomatic bones respectively.

\section{Zygomatic}

The zygomatic was rod like and formed movable articulations with the maxilla rostrally and quadrate caudally. The maxillary portion of zygomatic appeared flattened and was inserted to the posterior edge of the beak which was at a higher place than the insertion of palatine bones. These observations were in accordance with the findings of Indu et al., 2013, in green-winged macaw. However, Patki et al., 2009 in fowl, 
turkey, guinea fowl and crow reported that the zygomatic bones were thin, rod-like elongation of the rim of the upper back.

\section{Palatine}

The paired palatine bones were horizontal in position and formed a strong bone of the upper jaw. The anterior part of palatine was rod like which united with the palatine process of maxilla, behind which it was a fusiform flattened bony plate. A similar observation was noticed by Patki et al., 2009 who stated that in crows, the palatine was rod shaped cranially and plate like caudally. Contrarily, John et al., (2016) mentioned that palatine bone was roughly triangular at its proximal end and rod shaped towards the distal end. Nickel et al., (1977) reported that the palatine rod bone was shaped in fowl and pigeon while in duck and goose they were in the form of bony plates. The fusiform plates were inserted above the caudal part of maxilla, and enclosed a wide fusiform palatine cleft between them. The fusiform plates formed the lateral boundary of the posterior nares and their posterior ends articulated with the pterygoids.

Fig.1 Photograph showing the dorsal view of great indian horned owl skull

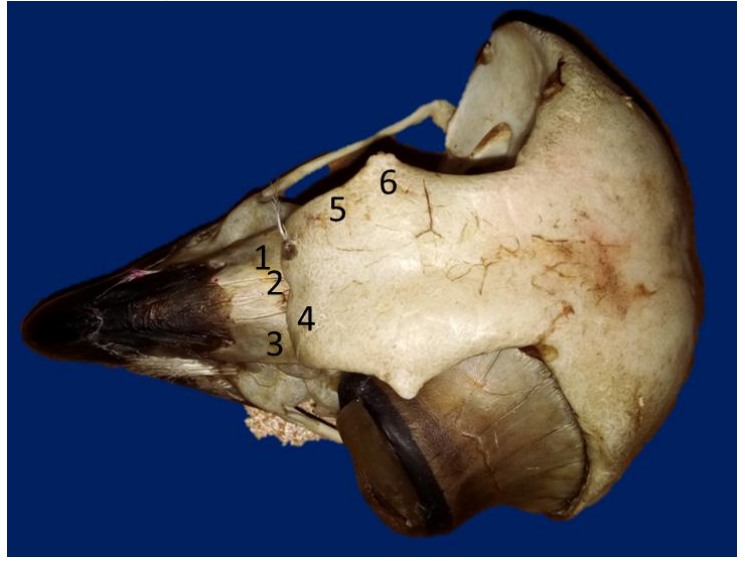

1.Lacrimal 2.Dorsal Lacrimal Process 3.Frontal of Nasal 4. Intermaxillary 5.Maxillary 6.Naso Frontal Hinge

Fig 2: Photograph showing of the lateral view of great indian horned owl skull

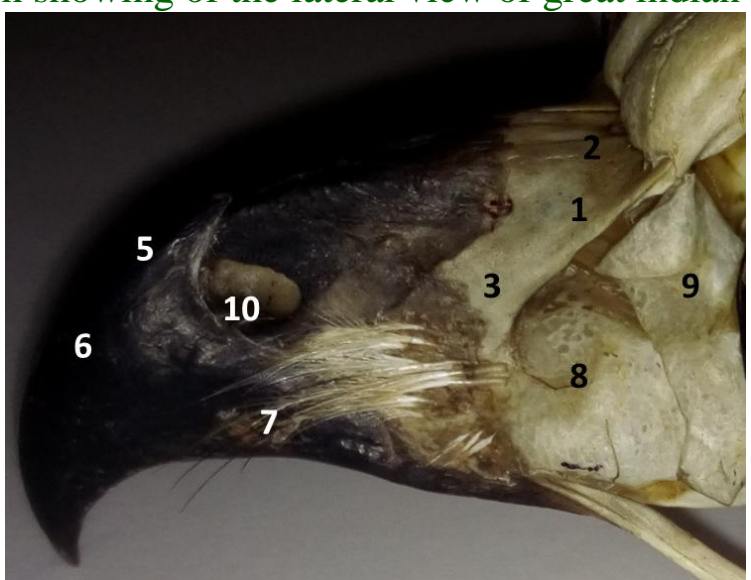

1.Frontal of nasal process 2 .Intermaxillary of nasal process 3. Maxillary of nasal process 4.naso frontal hinge 5.Premaxilla 6.Maxillary Premaxilla process 7.Frontal Premaxilla process

8.External naries 9. Anterior turbinates 10. Posterior turbinates 
Fig 3: Photograph Showing the ventral view Of Great Indian Horned Owl Skull

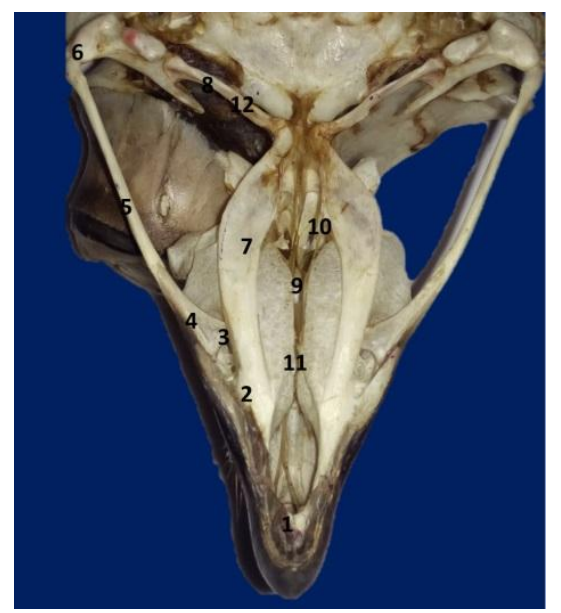

1.Palatin Process of Pre-maxilla 2. Palatin Process of Maxilla 3.Zygomatic of Maxilla 4.Jugal Process 5.Jugal 6.Quadratojugal 7.Palatine 8.Pterygoid 9.Vomer 10. Choane 11.Palatine Fissure

\section{Pterygoid Process}

Pterygoid was a thin short rod situated on either side of the vomer. It cranially articulated with the palatine bone, behind which it articulated with the parasphenoid process of presphenoid through a pterygoid process and caudally articulated with the quadrate. This was in accordance to the findings of John et al., 2016 in crow. Also Nickel et al., 1977 in domestic fowl had reported that the pterygoid articulated with palatine and sphenoid cranially and with quadrate caudally.

Vomer (Fig.3) was an unpaired thin bony plate situated in the median plane, and fused behind with the presphenoid and rostrally articulated with the fused maxilla as reported by Indu et al., 2013 in green-winged macaw and Getty, 1975 in fowl. Nickel et al., 1977 mentioned that the vomer was rudimentary in fowl and pigeon.

\section{Quadrate}

The quadrate bone served as a link between the skull and mandible and formed the basis of the mechanism of kinesis as reported by
Nickel et al., 1986 in domestic fowl. It was semicircular in shape. It presented three processes, the otic, orbital and articular. However, Patki et al., 2009 described that in fowl, turkey, guinea fowl and crow, the quadrate was quadrilateral in shape. A obtuse angle was noticed between the otic and orbital process as reported by John et al., 2016 in crow. The otic process formed a movable articulation with the articular groove of squamous temporal. The otic process was thick and semi-cylindrical rod and its summit showed a convex articular surface which was divided by a notch into two facets one small and one large. The articular process was strong, semi-circular thick and showed two condyles, a large medial and a small lateral condyle. The lateral condyle had two divisions of which the lateral division articulated with quadratojugal. The medial and lateral condyles presented on their summits, facets for articulation with their respective facets on the articular part of the mandible. Both the medial and lateral condyle were noticed as a fossa. The lower part of the medial condyle articulated with the caudal end of the pterygoid. 
The orbital process was directed towards the orbit. But these features different in domestic fowl as reported by Nickel et al., 1986. Further, Patki et al., 2009 observed that in crow, the caudo ventral part of the lateral. The mandible was ' $\mathrm{V}$ ' shaped with two curved rami

\section{Acknowledgement}

Authors are thankful to the Dean Rajiv Gandhi Institute of Veterinary Education and Research, Puducherry for providing the basic infrastructure for carrying out this research work.

\section{References}

Fitzgerald, T.C. (1969). The Coturnix Japanese quail, Anatomy and Physiology. The Iowa State University Press, Ames, Iowa. pp : 8-10.

Getty, R. (1975). Sisson and Grossman's the Anatomy of the Domestic Animals. Vol
II, 5th ed., W. B. Saunders Company, Philadelphia. 2095p.

John MA, Baba MA, Khan M, Sasan JS.: Anatomical Studies on the Skull of Crow (Corvus splendens) Article in International Journal of Scientific Research. 2016; 5-(2):189-193

Nickel, R., Schummer, A. and Seiferle, E. (1986). Anatomy of the Domestic Birds. Verlag Paul Parey, Berlin, Hamburg. 202p.

Patki, H.S., Lucy, K.M., Harshan, K.R., Chungath, J.J., and Indu, V.R. (2009). Gross and radiographic anatomy of the neurocranium of Indian common crow (Corvus sp.). Proceedings of the International Congress on Veterinary Anatomy of IAVA, Nov.4-6, Lucknow.

Indu V. R, Lucy K. M , Sreeranjini A. R, Maya S, Ashok N and Chungath J.J. (2013). Gross anatomy of the splanchnocranium in green-winged macaw. Tamilnadu J. Veterinary \& Animal Sciences, 9 (3):213 - 220.

\section{How to cite this article:}

Rajalakshmi, K., P. Sridevi and Siva Kumar, M. 2020. Gross Anatomy of the Splanchnocranium in the Great Indian Horned Owl (Bubo bengalensis). Int.J.Curr.Microbiol.App.Sci. 9(03): 1873-1878. doi: https://doi.org/10.20546/ijcmas.2020.903.217 